\title{
The Role of Microgravity in Cancer: A Dual-edge Sword
}

\author{
Reza Sahebi ${ }^{1}$, Maryam Aghaei $^{2}$, Sina Halvaei ${ }^{3}$, Akram Alizadeh ${ }^{1, *}$ \\ ${ }^{1}$ Cellular and Molecular Research Center, Shahrekord University of Medical Sciences, \\ Shahrekord, Iran \\ ${ }^{2}$ Skin Diseases and Leishmaniasis Research Center, Isfahan University of Medical \\ Sciences, Isfahan, Iran \\ ${ }^{3}$ School of Biology, College of Science, University of Tehran, Tehran, Iran \\ * Corresponding author: Akram Alizadeh, Cellular and Molecular Research Center, \\ Shahrekord University of Medical Sciences, Shahrekord, Iran. E-mail: alizadehbio@ \\ gmail.com
}

DOI: $10.21859 / \mathrm{mci}-01036$

Submitted: 18 May 2017

Revised: 20 June 2017

Accepted: 25 June 2017

ePublished: 1 July 2017

\section{Keywords:}

Weightlessness

Spheroids

Immune Responses

\begin{abstract}
Since human beings could travel beyond the earth atmosphere, scientists started to investigate the effect of microgravity on human cells. Microgravity has different effects on normal and cancer cells, but the related mechanisms are not well-known till now. The aim of the present review is to focus on the consequences of exposing the cancer cells to reduced gravity. Some cancer cells organize three-dimensional structures under microgravity. Obviously, microgravity is an external stress, which can affect cell proliferation, apoptosis, cytoskeleton and signaling pathways. In addition, it touches immune-related components, regulates immune responses, and implicates immune cell activation. Low mutation aggregation and cancer rate in astronauts may lead to use microgravity as a therapeutic approach. However, it reduces the invasion and migration in some types of cancer cells, triggers the oncogenic signaling pathways including KRAS, and inhibits proliferation in normal lymphocytes. In conclusion, using microgravity as a therapeutic method in cancer treatment needs to be more investigated on both cancer and normal cells, and might not become true in the near future.
\end{abstract}

(C) 2017. Multidisciplinary Cancer Investigation

\section{INTRODUCTION}

Gravity is a ubiquitous force, which affects all the creatures on the earth. After man stepping on the moon in 1969, the importance of the gravity became clearer. Astronauts showed various physiological changes under microgravity condition on the space [1]. Initial investigations about the effect of microgravity on human cells were performed through the US Skylab Program within the early 1970s. The aim of these studies was to survey the physiological and biomedical changes through mimicking microgravity on the earth [2]. The results showed that all the biological living systems, whether a complicated organism or single cell, are affected by surrounding environment and adapted to its changes. The human embryonic cells, WI 38 were cultivated in the Skylab III for about 28 days and the results revealed that the growth rate, chromosome banding, mitotic index or cell cycle were similar to human cells on earth $[3,4]$. However, there were differences between the Skylab III and on-earth cell cultured media in terms of consuming the components. Raised glucose concentrations in the Skylab III cell-cultured media suggested that micro- gravity altered cell metabolism. Furthermore, extracellular matrix, cell polarization and cell-cell interaction were different between both Skylab III and on-earth cell-cultured media $[5,6]$. Because of the space flights' impacts on astronauts, the study of normal cells under microgravity condition was focused. For instance, to study the effect of spaceflights on human cardiocytes, rat neonatal cardiomyocytes were cultured under less than $1 \mathrm{~g}$ gravity. Protein synthesis of rat neonatal cardiomyocytes decreased under minimal gravity, while apoptosis, cell viability, and protein degradation stayed stable [7]. In an additional study, evaluations showed that microgravity reduced the diabetic-associated genes including HNF1A knockout in the pancreatic cell [8]. In addition to the assessment of the normal cells, some studies focused on the effects of microgravity on cancer cells from different viewpoints. Several biological processes, including apoptosis, cytoskeleton, adhesion/extra-cellular matrix (ECM), proliferation, cell cycle, DNA repair and DNA replication, stress response, proteolysis, enzyme binding, transcription factor binding, migration, angiogen- 
esis, and signal transduction were differentially expressed in cancer cells $[9,10]$. The aim of the present review is to focus on the consequences of exposing the cancer cells to reduced gravity. Previously, some studies reviewed related articles till 2013 [11, 12], so the present article is included post-2013 studies. In this review, different effects of microgravity on cancer cell behavior and immune responses are discussed. Some recent studied genes and proteins in cancer cells and their alternation through the reduced gravity are summarized. Finally, the therapeutic application of microgravity in far future is pointed out.

\section{EFFECT OF MICROGRAVITY ON CANCER CELL BEHAVIOR}

\section{Viability and Apoptosis}

Several studies have shown the inhibitory effects of microgravity on cancer cells viability and growth. Inhibition of an anti-apoptotic protein, BCL-2, and inducing the apoptosis-related proteins, PARP, p-53 and Bax in ml-1 thyroid cancer cells has been demonstrated, through the simulated microgravity condition [10]. The Western blot analysis of BL6-10 melanoma cellular proteins discovered the Caspase-3, 7 and 8 up-regulation and Bnip3 and BCL2 down-regulation. Moreover, through the reduction of NF- $\kappa \mathrm{B}$ pathway regulating molecules including Uev1A, TICAM, TRAF2, and TRAF6, an apoptosis suppressor complex, NF- $\mathrm{kB} / \mathrm{p} 65$ is localized in the cytoplasm [13]. In conclusion, microgravity affects cancer cells by inhibiting survival signaling pathways and inducing programmed cell death. The CAV1 protein is a gravy-sensitive protein, which regulates cellular proliferation, differentiation and apoptosis [14], and decreases in cancer cells after $72 \mathrm{~h}$ exposing to microgravity [15].

\section{Growth and Proliferation}

Studies have indicated that cell cycle regulating proteins like CyclinD 1 and B1 were down-regulated under simulated microgravity in breast and colorectal cancers $[10,16]$. Recently, Kim et al. have studied the effect of microgravity on Hodgkin's lymphoma cancer cells [17] in comparison with normal human dermal fibroblast cells. Interestingly, the proliferation of lymphoma cancer cells was inhibited, and microgravity led to cell death; but normal cells were not affected [17]. ATM/ATR and CDK1/2 proteins are essential for cell cycle transition from $S$ to $G 2$ and decreased under microgravity. The flow-cytometery analysis confirmed that the number of cancer cells in the G2 phase are reduced [13]. Similar findings have been improved in breast and lung cancers $[15,16]$. Also, the colony formation assay on cancer cells (melanoma, colorectal and leukemia) revealed that microgravity diminishes the cancer cell ability to form colonies $[10,13]$. Briefly, reduced gravity disturbs cell cycle controlling genes and proteins, so prevents cancer cells from proliferation and forming spherical colonies.

\section{Extra-cellular Matrix and Cytoskeleton}

Microgravity can cause some changes in ECM and cytoskeletal proteins in cultured cells and triggers spheroid formation in some types of cancer cells [18]. Spheroids are three-dimensional (3D) cell architecture structures, which can reflect the physiological status of the tumor to some extent [9]. Modifying signaling pathways, the quantity of ECM and 3D growth associated proteins may interact in spheroid formation [18]. Studies on FTC-133 follicular thyroid cancer cell line revealed that the expression of VEGF, EGF and CTGF are up-regulated under microgravity in both two-dimensional (2D) and 3D cultures, but the expression of EGF in $3 \mathrm{D}$ is much higher than $2 \mathrm{D}$ culture, and the expression of CTGF in $2 \mathrm{D}$ is much higher than $3 \mathrm{D}$ culture $[19,20]$. Both EGF and CTGF implement proliferation and the difference between their expression in $2 \mathrm{D}$ and $3 \mathrm{D}$ culture shows their different roles through the environment changes. The Ml-1 thyroid cancer spheroids overexpressed intermediate filaments, vimentin and vinculin, in addition to ECM-related proteins, collagen type I and III, laminin, fibronectin, chondroitin sulfate compared with control spheroids [10]. In this regards, mass spectrophotometry analysis indicated that integrin a-5 chains, myosin-10 and filamin B found in FTC-133 cells mediates cell binding to fibronectin and enhances $3 \mathrm{D}$ growth [16]. Kopp et al. have revealed that the accumulation of F-actin and other cytoskeletal associated proteins toward the breast cancer cells' membrane directed to change the cancer cells' shape and form spheroid [21]. Previously, they had conducted similar study on the thyroid cancer cells and discovered parallel findings [20]. Cytokines, IL-6 and IL-8 regulate integrin beta-1, talin-1, Ki-67, and beta-actin, and mediate the spheroid formation [22]. Another study on thyroid cancer cells confirmed these findings. Bioinformatics analysis revealed that simulated microgravity promoted the overexpression of $3 \mathrm{D}$ growth-related proteins and avoided extreme accumulation of exogenous proteins. While structural proteins related genes are up-regulated [18]. After 22 seconds exposing to microgravity, the F-actin and cytokeratin cytoskeleton changed in thyroid cancer cells [23], and PXN, VCL, and PTK2 proteins localized around the focal adhesion complex and led to spheroid formation [24]. As shown in Table 1, ECM and cytoskeleton controlling genes, including $A C T B, K R T 80$, OPN, FN, COL4A5, LIMA1, TUBB, and PFN1 modify under microgravity. It seems that cancer cells remodeled their ECM and cytoskeleton as an adaptive response. To sum up, microgravity causes some changes in cell-cell interactions, cancer cells adhesion, migration and invasion. 
Sahebi et al.

Table1: Microgravity-induced Gene Expression Alternation

\begin{tabular}{|c|c|c|c|c|c|c|}
\hline $\begin{array}{l}\text { Type of } \\
\text { Cancer }\end{array}$ & Cell Line & $\begin{array}{l}\text { Type of Cell } \\
\text { Culture }\end{array}$ & Gene & $\uparrow$ & $\downarrow$ & Ref. \\
\hline \multirow[t]{4}{*}{$\begin{array}{l}\text { Follicular } \\
\text { Thyroid Cancer }\end{array}$} & $\mathrm{ml}-1$ & $2 \mathrm{D}$ & $\begin{array}{l}\text { ACTB, KRT80, OPN, FN } \\
\text { COL4AS, LIMA1, MTSS1 }\end{array}$ & * & * & {$[23]$} \\
\hline & FTC-133 & $2 \mathrm{D}$ & $\begin{array}{c}\text { ACTB, TUBB, PFN-1, ERK2, Casp9, FLT1, FLK1, OSP, } \\
\text { CPNE1, TGM2, NGAL, IL-6, IL-8, IL-7, CTGF } \\
\text { CAV2 } \\
\text { ACTB, TUBB, EGF, CTGF, VEGF, ERK1, ERK2, Casp9, } \\
\text { FLT1, FLK1, OSP, CPNE1, TGM2, NGAL, IL-6, IL-8, } \\
\text { IL-17 } \\
\text { CAV1, CAV2, CTGF, PRKCA, ITGB1, MMP3 }\end{array}$ & * & * & $\begin{array}{l}{[9,15} \\
19,20 \\
38,39\end{array}$ \\
\hline & Nthy-ori3-1 & $2 \mathrm{D}$ & $\begin{array}{c}\text { ACTB, TUBB, PFN-1, PKC, ERK1, ERK2, PKB, Casp9, } \\
\text { OSP, CPNE1, TGM2, NGAL, CollA1, IL-6, IL-8, IL-17 } \\
\text { VEGF } \\
\text { ACTB, TUBB, PFN-1, PKC, ERK1, ERK2, PKB, Casp9, } \\
\text { OSP, CPNE1, TGM2, NGAL, Col1A1, IL-6, IL-8, IL-17 }\end{array}$ & * & * & \\
\hline & $\begin{array}{c}\text { UCLA } \\
\text { RO82-W-1 }\end{array}$ & $3 \mathrm{D}$ & $\begin{array}{c}\text { VEGFA, VEGFD, MSN, MMP3 } \\
\text { ACTB, ACTA2, KRT8, TUBB, EZR, RDX, PRKCA, } \\
\text { CAV1, MMP9, PAI1, CTGF, MCP1 }\end{array}$ & * & * & {$[18]$} \\
\hline Breast Cancer & MCF-7 & $\begin{array}{l}2 \mathrm{D} \\
3 \mathrm{D}\end{array}$ & $\begin{array}{c}\text { IL8, VEGFA, FLT1, ESR1, PGR1 } \\
\text { ACTB, TUBB, EZR, RDX, FN1, VEGFA, FLK1, Casp9, } \\
\text { Casp3, PRKCA }\end{array}$ & * & * & {$[21]$} \\
\hline $\begin{array}{l}\text { Melanoma } \\
\text { Cells }\end{array}$ & BL6-10 & $2 \mathrm{D}$ & $\begin{array}{c}\text { Neil3, Nthl1, PARP, Ung, Brip1, Ercc8, Rad23, Rad51, } \\
\text { Xrcc2, Ku70, ATM }\end{array}$ & & * & {$[13]$} \\
\hline Leukemia & $\begin{array}{l}\text { DLD-1 } \\
\text { HL-60 }\end{array}$ & $2 \mathrm{D}$ & $\begin{array}{c}\text { CDK1, JUNB, MYC, HEY1 } \\
\text { CD117, CDK2, CCNE1, TFRC } \\
C D K 1, C D K 2, C D 117, M Y C, C D 105, C D 90 \\
C C N B 1, C D 71\end{array}$ & * & * & {$[10]$} \\
\hline $\begin{array}{l}\text { Colorectal } \\
\text { Cancer }\end{array}$ & MOLT-4 & $2 \mathrm{D}$ & $\begin{array}{c}\text { JUNB, CD117, CCNB1 } \\
\text { CDK1, MYC, ROMO1, CCNE1 }\end{array}$ & * & * & {$[10]$} \\
\hline Lung Cancer & $\mathrm{H} 460$ & $3 \mathrm{D}$ & Nanog, OCT-4 & & * & {$[15]$} \\
\hline
\end{tabular}

$\uparrow$ : Up-regulation, $\downarrow$ : Down-regulation.

\section{MICROGRAVITY AND IMMUNE SYSTEM RE- SPONSES}

Microgravity results in alternation of immune responses by modifying both immune system's compartments and cells. The effect of microgravity on the compartments of the immune system has been investigated in several studies. As most studied cancer cells under microgravity condition, thyroid cancer cells showed overexpression of inflammatory factors, IL-6, IL-7 and IL-17 proteins. In addition to these molecules, the toll-like receptor downstream protein, NGAL and pro-inflammatory cytokines activated protein, OPN are up-regulated in FTC-133 thyroid cancer cells [20]. Down-regulating the IL I-beta under the reduced gravity condition causes human macrovascular endothelial cells to proliferate and remodel their cytoskeleton faster than the control cells, which expose to normal earth gravity [27]. Researches about the effect of microgravity on immune cells such asmouse's leukocytes in space shuttle showed that mitogenesis of the lymph cells and activity of the cytotoxic T-cells (CTCs) are suppressed. Moreover, CTC released cytokines, which reduced and altered the function and proportions of T-cell subsets. In contrast, certainly accumula- tion of cytokines in spleen and thymus cells of space-flown rodents were reduced $[28,29]$. Other studies on the effect of on-earth microgravity on immune cells illustrated interleukin 1 [24], IL 3, IL 6, tumor necrosis factor, interferon $\alpha$ and $\gamma$ accumulations in them [30-32]. Under reduced gravity, human monocytic cell line, U937 maintains its capability to differentiate [27], and also down-regulating the IL I-beta caused alternation in the ubiquitous enzyme, protein kinase $\mathrm{C}$ distribution, through the cytosol and nucleus of immune cells [33]. In another study, scientists exposed mesenchymal stem cells (MSCs) to the simulated microgravity, and then injected them to the nude mice as an anticancer vaccine. Microgravity-treated MSCs showed increased MHC1 and HSPs proteins expression, and also induced Th1-mediated cytokine and CD8-dependent cytotoxic responses which altogether inhibited proliferation of lung cancer cells and reduced the tumor size and weight [34]. Moreover, the bioinformatics analysis has revealed that the NF- $\kappa B$ pathway was down-regulated by Notch 1 signaling. Then, NF- $\kappa B$ pathway mediated LPS genes, which played a key role in LPS-stimulated macrophage activation through the microgravity [8]. 


\section{POSSIBILITY OF A THERAPEUTIC AP- PROACH}

Low mutation aggregation and cancer rate in astronauts [35] may light this idea in someone's mind which microgravity might have the potential to be utilized as a therapeutic approach in cancer treatment. A summary of expression of the altered genes in different cancer cell lines has been mentioned in Table 1. However, our current understanding of microgravity impacts on cancer cells is still limited; there are some controversies among the related studies, which we discussed about them below. Evidently, there is a close crosstalk between cancer treatment and the immune system responses. Most of the immune responses dysregulations may be the cause of cancer occurrence or affect response to therapy [36]. There are some studies that confirm the effects of microgravity on immune cell activation, pro-inflammatory and inflammatory protein accumulation, and inducing cytokines secretion. Furthermore, microgravity inhibits proliferation of the cancer cells and increases the drug sensitivity in B lymphoma, liver, breast and non-small lung cancer [8]. CTGF, a connective tissue growth factor gene, is over-expressed in papillary thyroid carcinoma cells under microgravity and has a negative correlation with metastasis, tumor size and clinical stage [37]. Melanoma cancer cells' DNA repair molecules like PARP, Ercc8, Rad23, Rad51, and Ku70 are down-regulated at the levels of transcription and translation. Furthermore, DNA damage response mediating genes, p53, PCNA, ATM/ATR, and CDK1/2 significantly inhibited [13]. Invasion-related genes, MMP2 and MMP3 genes and other angiogenesis-related genes in cancer cells declined dependently of gravity $[9,14]$. Microarray analysis has discovered that MIR22HG as a tumor suppressor gene, 4.4 fold is up-regulated under zero gravity and this finding has been validated by q-PCR. Also, the downstream targets of MIR22HG, including SP1, CDK6 and CCNA2 were dysregulated [10].

In contrast, there are some studies which pointed the role of microgravity in favor of cancer cells. The migratory ability of human lung cancer cell lines of adenocarcinoma and squamous cell carcinoma increased after exposing to microgravity [38]. Researchers have found some evidences that show microgravity may induce some types of cancer like leukemia, lung, breast, ovarian, liver, head and neck cancers. No matter the cancer cells have been cultured on simulated microgravity or 1 g gravity, the KRAS oncogenic pathway is induced in them [8]. In this regard, cytogenesis results indicate that DNA repair and proliferation- related genes (including CCND1 and PCNA) are down-regulated in normal lymphocytes. Also, the expression of apoptotic genes (including $B a x$ ) was reduced. In conclusion, the accumulation of DNA damaged immune cells may cause malignancy [39]. As shown in Table 1, microgravity has dissimilar impacts on gene expression of various cancer cells. For example, a proto-oncogene, MYC, was down-regulated in leukemia and up-regulated in the colorectal cancer. Unlikely, another proto-oncogene, CD117, was up-regulated in leukemia and down-regulated in the colorectal cancer [10]. These results show different effects of microgravity on solid and liquid tumors. All in all, it seems too soon to decide about the microgravity therapeutic application in cancer. However, it can be concluded that microgravity alone might induce cancer but along with the other factors like chemotherapy and radiotherapy enhance the impression of the treatment.

\section{CONCLUSIONS}

Obviously, cancer cells consider microgravity as an external stress. Over-expression of cellular stress related proteins including HSP70 and ROS, and $\mathrm{Ca}^{2+}$ ion evidences this claim [37]. In the microgravity status, some cancer cells assemble to multicellular 3D constructs. Therefore, simulated microgravity may be applies as an inducing factor in tissue engineering and spheroid formation. Microgravity has various effects on the cell growth, proliferation, gene expression, production of soluble factors, cell signaling, ECM production, cytoskeletal organization and cell adhesion. Furthermore, it affects the expression of cytokines, interleukins and other immune- related compartments and activates immune cells. With regard to analytical approaches derived from spacebased investigations, it seems that microgravity could be used as an anti-tumor technology and therapeutic method in far future. Therefore, the effects of microgravity on both normal and cancer cells should be more studied.

\section{ACKNOWLEDGEMENTS}

Not applicable.

\section{CONFLICT OF INTEREST}

The authors have no conflict of interest.

\section{ETHICS APPROVAL}

Not applicable.

\section{REFERENCES}

1. Winnard A, Nasser M, Debuse D, Stokes M, Evetts S, Wilkinson $\mathrm{M}$, et al. Systematic review of countermeasures to minimise physiological changes and risk of injury to the lumbopelvic area following long-term microgravity. Musculoskelet Sci Pract. 2017;27 Suppl 1:S5-S14. DOI: 10.1016/j.msksp.2016.12.009 PMID: 28173932

2. Brown AH. From gravity and the organism to gravity and the cell. ASGSB Bull. 1991;4(2):7-18. PMID: 11537184

3. Johnston RS, Dietlein LF, editors. Biomedical results from Skylab. NASA SP-377. Biomedical Results from Skylab; 1977.

4. Montgomery PO, Jr., CookJE, Reynolds RC, Paul JS, Hayflick L, Stock D, et al. The response of single human cells to zero gravity. In Vitro. 1978;14(2):165-73. PMID: 352912

5. Lee EY, Lee WH, Kaetzel CS, Parry G, Bissell MJ. Interaction of mouse mammary epithelial cells with collagen substrata: regulation of casein gene expression and secretion. Proc Natl Acad Sci U S A. 1985;82(5):1419-23. PMID: 3856271

6. Kunz-Schughart LA, Kreutz M, Knuechel R. Multicellular spheroids: a three-dimensional in vitro culture system to study tumour biology. Int J Exp Pathol. 1998;79(1):1-23. PMID: 
9614346

7. Feger BJ, Thompson JW, Dubois LG, Kommaddi RP, Foster MW, Mishra R, et al. Microgravity induces proteomics changes involved in endoplasmic reticulum stress and mitochondrial protection. Sci Rep. 2016;6:34091. DOI: 10.1038/srep34091 PMID: 27670941

8. Mukhopadhyay S, Saha R, Palanisamy A, Ghosh M, Biswas A, Roy $\mathrm{S}$, et al. A systems biology pipeline identifies new immune and disease related molecular signatures and networks in human cells during microgravity exposure. Sci Rep. 2016;6:25975. DOI: $10.1038 / \operatorname{srep} 25975$ PMID: 27185415

9. Kimlin LC, Casagrande G, Virador VM. In vitro three-dimensional (3D) models in cancer research: an update. Mol Carcinog. 2013;52(3):167-82. DOI: 10.1002/mc.21844 PMID: 22162252

10. Vidyasekar P, Shyamsunder P, Arun R, Santhakumar R, Kapadia NK, Kumar R, et al. Genome Wide Expression Profiling of Cancer Cell Lines Cultured in Microgravity Reveals Significant Dysregulation of Cell Cycle and MicroRNA Gene Networks. PLoS One. 2015;10(8):e0135958. DOI: 10.1371/journal. pone.0135958 PMID: 26295583

11. BeckerJL, Souza GR. Using space-based investigations to inform cancer research on Earth. Nat Rev Cancer. 2013;13(5):315-27. DOI: $10.1038 / \mathrm{nrc3507}$ PMID: 23584334

12. Jhala DV, Kale RK, Singh RP. Microgravity alters cancer growth and progression. Curr Cancer Drug Targets. 2014;14(4):394406. PMID: 24720362

13. Zhao T, Tang X, Umeshappa CS, Ma H, Gao H, Deng Y, et al. Simulated Microgravity Promotes Cell Apoptosis Through Suppressing Uev1A/TICAM/TRAF/NF-kappaB-Regulated Anti-Apoptosis and p53/PCNA- and ATM/ATR-Chk1/2-Controlled DNA-Damage Response Pathways. J Cell Biochem. 2016;117(9):2138-48. DOI: 10.1002/jcb.25520 PMID: 26887372

14. Chang D, Xu H, Guo Y, Jiang X, Liu Y, Li K, et al. Simulated microgravity alters the metastatic potential of a human lung adenocarcinoma cell line. In Vitro Cell Dev Biol Anim. 2013;49(3):170-7. DOI: 10.1007/s11626-013-9581-9 PMID: 23404217

15. Pisanu ME, Noto A, De Vitis C, Masiello MG, Coluccia P, Proietti $S$, et al. Lung cancer stem cell lose their stemness default state after exposure to microgravity. Biomed Res Int. 2014;2014:470253. DOI: 10.1155/2014/470253 PMID: 25276790

16. Masiello MG, Cucina A, Proietti S, Palombo A, Coluccia P, D'Anselmi F, et al. Phenotypic switch induced by simulated microgravity on MDA-MB-231 breast cancer cells. Biomed Res Int. 2014;2014:652434. DOI: 10.1155/2014/652434 PMID: 25215287

17. Kim YJ, Jeong AJ, Kim M, Lee C, Ye SK, Kim S. Time-averaged simulated microgravity (taSMG) inhibits proliferation of lymphoma cells, L-540 and HDLM-2, using a 3D clinostat. Biomed Eng Online. 2017;16(1):48. DOI: 10.1186/s12938-017-03378 PMID: 28427408

18. Riwaldt S, Bauer J, Wehland M, Slumstrup L, Kopp S, Warnke E, et al. Pathways Regulating Spheroid Formation of Human Follicular Thyroid Cancer Cells under Simulated Microgravity Conditions: A Genetic Approach. Int J Mol Sci. 2016;17(4):528. DOI: 10.3390/ijms 17040528 PMID: 27070589

19. Pietsch J, Ma X, Wehland M, Aleshcheva G, Schwarzwalder A, Segerer J, et al. Spheroid formation of human thyroid cancer cells in an automated culturing system during the Shenzhou-8 Space mission. Biomaterials. 2013;34(31):7694-705. DOI: 10.1016/j. biomaterials.2013.06.054 PMID: 23866977

20. Kopp S, Warnke E, Wehland M, Aleshcheva G, Magnusson NE, Hemmersbach R, et al. Mechanisms of three-dimensional growth of thyroid cells during long-term simulated microgravity. Sci Rep. 2015;5:16691. DOI: 10.1038/srep16691 PMID: 26576504

21. Kopp S, Slumstrup L, Corydon TJ, Sahana J, Aleshcheva G, Islam $\mathrm{T}$, et al. Identifications of novel mechanisms in breast cancer cells involving duct-like multicellular spheroid formation after exposure to the Random Positioning Machine. Sci Rep. 2016;6:26887. DOI: 10.1038/srep26887 PMID: 27230828

22. Svejgaard B, Wehland M, Ma X, Kopp S, Sahana J, Warnke E, et al. Common Effects on Cancer Cells Exerted by a Ran- dom Positioning Machine and a 2D Clinostat. PLoS One. 2015;10(8):e0135157. DOI: 10.1371/journal.pone.0135157 PMID: 26274317

23. Ulbrich C, Pietsch J, Grosse J, Wehland M, Schulz H, Saar K, et al. Differential gene regulation under altered gravity conditions in follicular thyroid cancer cells: relationship between the extracellular matrix and the cytoskeleton. Cell Physiol Biochem. 2011;28(2):185-98. DOI: 10.1159/000331730 PMID: 21865726

24. Bauer J, Kopp S, Schlagberger EM, Grosse J, Sahana J, Riwaldt $S$, et al. Proteome Analysis of Human Follicular Thyroid Cancer Cells Exposed to the Random Positioning Machine. Int J Mol Sci. 2017;18(3):546. DOI: 10.3390/ijms18030546 PMID: 28273809

25. Ma X, Wehland M, Aleshcheva G, Hauslage J, Wasser K, Hemmersbach $\mathrm{R}$, et al. Interleukin- 6 expression under gravitational stress due to vibration and hypergravity in follicular thyroid cancer cells. PLoS One. 2013;8(7):e68140. DOI: 10.1371/journal. pone.0068140 PMID: 23844163

26. Riwaldt S, Bauer J, Pietsch J, Braun M, Segerer J, Schwarzwalder A, et al. The Importance of Caveolin-1 as Key-Regulator of Three-Dimensional Growth in Thyroid Cancer Cells Cultured under Real and Simulated Microgravity Conditions. Int J Mol Sci. 2015;16(12):28296-310. DOI: $10.3390 /$ ijms161226108 PMID: 26633361

27. Villa A, Versari S, Maier JA, Bradamante S. Cell behavior in simulated microgravity: a comparison of results obtained with RWV and RPM. Gravit Space Biol Bull. 2005;18(2):89-90. PMID: 16038099

28. Sonnenfeld G, Mandel AD, Konstantinova IV, Berry WD, Taylor GR, Lesnyak AT, et al. Spaceflight alters immune cell function and distribution. J Appl Physiol (1985). 1992;73(2 Suppl):191S-5S. PMID: 1526951

29. Gridley DS, Slater JM, Luo-Owen X, Rizvi A, Chapes SK, Stodieck LS, et al. Spaceflight effects on T lymphocyte distribution, function and gene expression. J Appl Physiol (1985). 2009;106(1):194-202. DOI: 10.1152/japplphysiol.91126.2008 PMID: 18988762

30. Chapes SK, Morrison DR, Guikema JA, Lewis ML, Spooner BS. Cytokine secretion by immune cells in space. J Leukoc Biol. 1992;52(1):104-10. PMID: 1640164

31. Miller ES, Koebel DA, Sonnenfeld G. Influence of spaceflight on the production of interleukin- 3 and interleukin- 6 by rat spleen and thymus cells. J Appl Physiol (1985). 1995;78(3):810-3. PMID: 7775323

32. Reynolds RJ, Day SM. Mortality among US astronauts: 19802009. Aviat Space Environ Med. 2010;81(11):1024-7.

33. Schmitt DA, Hatton JP, Emond C, Chaput D, Paris H, Levade T, et al. The distribution of protein kinase $\mathrm{C}$ in human leukocytes is altered in microgravity. FASEB J. 1996;10(14):1627-34. PMID: 9002555

34. Li J, Chen J, Li X, Qian Y. Vaccination efficacy with marrow mesenchymal stem cell against cancer was enhanced under simulated microgravity. Biochem Biophys Res Commun. 2017;485(3):606-13. DOI: 10.1016/j.bbrc.2017.01.136 PMID: 28238782

35. Worth Jr MH, Manning FJ, Longnecker DE. Review of NASA's longitudinal study of astronaut health. USA: National Academies Press; 2004.

36. Corthay A. Does the immune system naturally protect against cancer? Front Immunol. 2014;5:197. DOI: 10.3389/fimmu.2014.00197 PMID: 24860567

37. Zhang Y, Wang H, Lai C, Wang L, Deng Y. Comparative proteomic analysis of human SH-SY5Y neuroblastoma cells under simulated microgravity. Astrobiology. 2013;13(2):143-50. DOI: 10.1089/ast.2012.0822 PMID: 23421552

38. Chung JH, Ahn CB, Son KH, Yi E, Son HS, Kim HS, et al. Simulated Microgravity Effects on Nonsmall Cell Lung Cancer Cell Proliferation and Migration. Aerosp Med Hum Perform. 2017;88(2):82-9. DOI: 10.3357/AMHP.4647.2017 PMID: 28095951

39. Kumari R, Singh KP, Dumond JW, Jr. Simulated microgravity decreases DNA repair capacity and induces DNA damage in human lymphocytes. J Cell Biochem. 2009;107(4):723-31. DOI: 10.1002/jcb.22171 PMID: 19415677 